\title{
BMJ Open Poor housing conditions in association with child health in a disadvantaged immigrant population: a cross-sectional study in Rosengård, Malmö, Sweden
}

\author{
Anna Oudin, Jens C Richter, Tahir Taj, Lina Al-nahar, Kristina Jakobsson
}

To cite: Oudin A, Richter JC, Taj T, et al. Poor housing conditions in association with child health in a disadvantaged immigrant population: a cross-sectional study in Rosengård, Malmö, Sweden. BMJ Open 2016;6: e007979. doi:10.1136/ bmjopen-2015-007979

- Prepublication history and additional material is available. To view please visit the journal (http://dx.doi.org/ 10.1136/bmjopen-2015007979).

Received 17 February 2015 Revised 23 July 2015 Accepted 30 July 2015

CrossMark

\section{Laboratory Medicine,} Occupational and Environmental Medicine, Lund University, Lund, Sweden

\section{Correspondence to} Dr Anna Oudin; anna.oudin@umu.se

\section{ABSTRACT}

Objectives: To describe the home environment in terms of housing conditions and their association with child health in a disadvantaged immigrant population.

Design: A cross-sectional observational study. Setting: Enrolment took place during 2010-2011 in Rosengård, Malmö, Sweden.

Participants: Children aged $0-13$ years in 2 study neighbourhoods were recruited from local health records and from schools. 359 children participated, with a participation rate of $40 \%$. Data on health, lifestyle and apartment characteristics from questionnaire-led interviews with the mothers of the children were obtained together with data from home inspections carried out by trained health communicators.

Outcome measures: Logistic regression analysis was used to estimate ORs for various health outcomes, adjusted for demographic information and lifestyle factors.

Results: The housing conditions were very poor, especially in one of the study neighbourhoods where $67 \%$ of the apartments had been sanitised of cockroaches, $27 \%$ were infested with cockroaches and $40 \%$ had a visible mould. The association between housing conditions and health was mostly inconclusive, but there were statistically significant associations between current asthma and dampness (OR=4.1, 95\% Cl 1.7 to 9.9), between asthma medication and dampness (OR=2.8, 95\% $\mathrm{Cl} 1.2$ to $6.4)$, and between mould and headache ( $\mathrm{OR}=4.2,95 \%$ $\mathrm{Cl} 1.2$ to 14.8). The presence of cockroaches was associated with emergency care visits, with colds, with headache and with difficulty falling asleep, and worse general health was associated with mould and presence of cockroaches.

Conclusions: The associations between dampness and asthma, and the association between mould and headache, are in line with current knowledge. The presence of cockroaches seemed to be associated with various outcomes, including those related to mental well-being, which is less described in the literature. The results of the present study are hypothesis generating and provide strong incentives for future studies in this study population.

\section{Strengths and limitations of this study}

- A disadvantaged population was studied in a society that is one of the world's most socioeconomically equal (Sweden).

- Associations between such poor housing and health (or child health) have similarly not been described in Sweden since the mid-1900s.

- Data were collected in a standardised way by experienced health communicators speaking the native language of the family.

- The study was cross-sectional and therefore descriptive. Causal inference cannot be drawn.

- Health data were mainly self-reported.

\section{BACKGROUND}

This study was initiated in 2008 when the public became aware of the extremely poor housing conditions in certain areas of Rosengård, a predominantly immigrant neighbourhood in the city of Malmö in southern Sweden. Apartments in the affected neighbourhood in Rosengård (Herrgården) were overcrowded, damp, affected by mould, and infested by cockroaches and other vermin. Toilets and bathrooms were often out of order. Furthermore, anecdotal reports from local health workers suggested that children from Herrgården were over-represented in terms of respiratory diseases and healthcare use.

Children's health is especially vulnerable to poor housing conditions for several reasons. Not only is children's exposure usually higher in terms of time spent indoors, but children have much higher respiratory rates relative to their body weight than adults, and their behaviour differs with more time spent on the floor and placing objects in their mouths. Moreover, their immune systems and metabolic capacities are less developed and they have fewer 
opportunities to actively influence their environment. ${ }^{1}$ The home environment during early life is thus an important source of exposure to chemical, biological, and physical agents.

Poor housing conditions have been reported to be associated with respiratory infections, asthma, and mental health in children, ${ }^{2}$ and poor housing conditions play a role in the association between income inequality and child health. ${ }^{34}$ Associations between poor housing, especially mould and dampness, and childhood asthma are well-established worldwide. ${ }^{5-10}$ Moreover, exposure to high levels of cockroach allergens can contribute to asthma severity in inner-city children in the USA. ${ }^{11}$

Sweden is considered one of the most socioeconomically equal countries in the world with a Gini coefficient of 0.32 in 2009. Nevertheless, there are still substantial inequalities within the country. An immigrant child in Sweden (a child who is born outside of Sweden or a child whose parents were both born outside of Sweden) has a five times higher risk of living in an economically disadvantaged household compared with children whose parents were both born in Sweden. ${ }^{12}$ Segregation in major cities has been described as a major social problem in Swedish society, ${ }^{13}$ and in Malmö there are inequalities in children's health with respect to social and ethnic gradients. ${ }^{14}$ Moreover, Malmö has the highest rate of child poverty in Sweden with $32 \%$ of all children in 2012 living in economically disadvantaged households. In Rosengård, the rate of child poverty in 2012 was $50 \%$ compared with an overall rate of $12 \%$ in Sweden as a whole. ${ }^{15}$ Furthermore, income inequalities are increasing. ${ }^{15}$ According to the Organisation for Economic Co-operation and Development (OECD), Sweden was the world leader in income equality in 1995 but had dropped to 14th place by 2010 .

The neighbourhood of Herrgården in Rosengård has an official population of almost 5000 people although it was originally planned for roughly 3000 inhabitants. According to some estimates, as many as 8000 persons currently live there. ${ }^{16}$ The population of Herrgården is on the margin of Swedish society and was exposed to home environments that are unimaginable for most Swedes. Associations between such poor housing conditions and various health outcomes have, to the best of our knowledge, not been described in Sweden since the establishment of the Swedish welfare state in the mid-1900s. Cockroach allergens have, for example, previously been reported to be rare in Swedes ${ }^{17}$ and are not included as standard allergens in skin prick tests (SPTs) in Sweden.

This study was initiated at the clinical department of Occupational and Environmental Medicine, Medicinsk Service, Region Skåne, when the main property owner in Herrgården, after massive media attention, received an injunction from local authorities to perform extensive repairs in more than 800 housing units within a set length of time. This provided a unique opportunity to examine whether the health of children living in this neighbourhood had been affected by poor indoor environment, and if their health would improve after the repairs were made. As the main study design is a prospective intervention study looking at the effect of the housing renovations on respiratory health in vulnerable children, children with respiratory symptoms were oversampled at baseline. The aim of our study is to describe the home environment in terms of housing conditions and its association with health at baseline in this disadvantaged immigrant population in Malmö, Sweden.

\section{MATERIAL AND METHODS}

\section{Study area and recruitment}

The study area was defined as the affected neighbourhood of Herrgården and a selected part of the adjoining neighbourhood of Törnrosen with similar infrastructure. Both study neighbourhoods are subdistricts within Rosengård, Malmö, in southern Sweden. The buildings are of similar age and construction, but the selected area in Törnrosen had had appropriate upkeep in contrast to the main part of the buildings in Herrgården, where upkeep had been severely neglected by the proprietors for many years.

Recruitment of study participants was carried out in two ways. In early 2010, electronic patient registries between 2007 to 2010 at the two local primary healthcare centres (PHCs) serving the area were searched for all children between the ages of 0 and 13 years (the cut-off date was 1 May 2010) with diagnoses of asthma or other respiratory diseases and who were registered as living in the defined study area at the time of the documented healthcare contact. The specialised asthma nurses' records were also checked as were the enrolment lists of information sessions for families with children with asthma that had been held at the PHCs. This identification of index children was carried out by the same team of investigators in both PHCs with similar procedures. To obtain a subgroup where children with respiratory symptoms were not oversampled, the sampling was expanded to include children from the study area who were aged between 6 and 13 years from class lists that were obtained from the local school. All families of the children received written invitations from the researchers and the PHCs to participate in the study. It was explained that the study would entail a home visit and that data would be collected on the children (regardless of whether or not they were symptomatic at the time of the home visit), their siblings, and parents living in the same household. If no replies to the written invitations were received, the investigators attempted to contact the families by telephone. If families chose to participate, a home visit was scheduled during which health communicators fluent in the family's native language visited the apartment. All initial visits were carried out between 27 May 2010 and 29 May 2011. At the start of the home visit, informed written consent in the native language of 
the family for participation in the study was obtained from the parents.

Interview questionnaires were used to collect demographic information for all core family members in the household (including country of origin, place of birth, and duration of residence in Sweden), physical apartment characteristics (number of rooms, number of regular occupants, presence of pests), subjective exposure assessment in the various rooms (dampness, mould) and information about lifestyles and behaviours (smoking, water pipes, incense, pets). In addition, questionnaires were used to collect health information for children aged $0-13$ years at the time of visit with a main focus on respiratory, allergic, and dermal symptoms, using questions from a national Children's Environmental Health Survey of 2003. The questionnaires also gathered information on physician-diagnosed diseases such as asthma, allergic rhinitis, and eczema. The mothers were also asked about breast feeding practices for all children. Age of the mother at the time of birth of the child as well as the number of siblings were calculated from the available data. Finally, a standardised visual assessment of multiple areas of all homes was carried out at the time of the home visit by the health communicators who had undergone training in home assessments. Documented in the form of a checklist, the assessment scored the extent of moisture damage, visible mould, and mouldy odour in all rooms to which access was granted.

\section{Background variables}

We used the variables age at the time of the health visit, sex, born in Sweden (yes/no), mother's age at birth, number of older siblings, number of months with exclusive breast feeding, father's education (university level or lower), mother's education (university level or lower), father working full time (yes/no), and mother working full time (yes/no) for sociodemographic description.

\section{Outcome variables}

We used self-reported data (with maternal report as proxy) on general health ('Good' and 'Very good' vs 'Fair', 'Poor', and 'Very poor'), current asthma (defined as a doctor's diagnosis in Sweden or abroad and at least one episode of wheeze during the past 12 months or wheeze more than four times in the past 12 months or asthma medication during the past 12 months and at least one episode of wheeze during the past 12 months), the use of asthma medication in the past 12 months, emergency care in the previous 3 months (2 times or more vs 0 or 1 time), colds in the past 3 months ( $\geq 2$ vs 0 or 1 ), otitis media in the past 3 months ( $\geq 1$ vs 0 ), headache in the past month (yes/no), stomach pain or nausea in the past month (yes/no), feelings of stress in the past month (yes/no), difficulty concentrating in the past month (yes/no), difficulty falling asleep in the past month (yes/no), and fatigue (yes/no). SPTs were performed within 3 weeks after the home visit and read and documented by experienced specialised nurses. SPTs with a standard panel for aeroallergens, including moulds, house dust mites, plants, animal dander, and, in addition, cockroach (Bla g 2), were performed on all participants who were willing to be included. All tests were read after $15 \mathrm{~min}$. Control tests were carried out with histamine and saline. If a positive reaction occurred to histamine with a negative reaction to normal saline, the SPT was deemed valid. If the reaction to an antigen was at least half the size of the histamine reaction, the test was judged as positive. Any smaller or no reaction was deemed a negative result.

\section{Exposure variables}

The following exposure variables that were objectively assessed by the health communicators were used in the current study: 'Dampness in kitchen, bathroom, or toilet', 'Dampness in bedrooms or living room', 'Mould smell or visible mould in bedrooms or living room', 'Visible mould anywhere in apartment', and 'Mould smell anywhere in apartment'. The variables were defined as 'yes' if any of a list of observations were made. For example, 'Dampness in kitchen, toilet, or bathroom' was defined as a 'yes' if at least one of the following were observed: floor drain to the toilet; bubbles in the plastic mats in the toilet, kitchen, or bathroom; a dripping faucet in the bathroom or kitchen; visible damp patches in the bathroom or kitchen; visible moisture stains in the bathroom or kitchen; visible moisture stains on the toilet; difficulty turning off the faucet in the bathroom or kitchen; leaking or dripping water pipes in the bathroom or kitchen; or inefficient floor drainage in the bathroom. We also created a variable describing the total number of factors from the list of factors aforementioned indicating dampness in the kitchen, bathroom or toilet as well as for mould or mould smell in bedrooms or living room. To describe exposure to cockroaches, we were restricted to self-reported data and the variables 'Cockroaches in the apartment now (yes/no)' or 'Apartment sanitised from cockroaches (yes/no)'. Furthermore, we defined a variable on environmental tobacco smoke (ETS) as anyone smoking at home (mother or father or someone else smoking at home every day, yes/no) and a variable for the average number of persons living in the apartment per room (bedrooms and living room) in the apartment as an indicator of crowdedness.

\section{Statistical analysis}

We used descriptive statistics of the background variables and the exposure variables to describe differences in the background variables between the participating children of the two neighbourhoods, Herrgården and Törnrosen. The differences between the two study neighbourhoods were tested with Fisher's exact test for binary variables, and with the Mann-Whitney test for continuous variables. For the outcome variables, we stratified the children according to neighbourhood, as well as according to whether the child was an index child, a sibling of an index child, or if the child was recruited from the local 
schools or was a sibling to a child recruited from the local schools. This was necessary because index children were sampled from local health registers, and children with respiratory health problems could thus be expected to be oversampled in index children and in siblings of index children.

In order to investigate associations between the outcome variables and the exposure variables, we chose two objectively assessed exposure variables described above: 'Mould smell or visible mould in bedrooms or living room' and 'Dampness in kitchen, toilet or bathroom'. The reason for analysing mould and dampness separately was that indicators for dampness were very common in the study setting, and that we wanted to also use a more conservative measure. The overlap between the variables was large; all but one apartments categorised with 'Mould smell or visible mould in bedrooms or living room', were also categorised with 'Dampness in kitchen, toilet or bathroom'. We defined a variable for exposure to cockroaches according to the self-reported variables 'Cockroaches in the apartment now' or 'Apartment sanitised from cockroaches', and a 'yes' in either of these two variables was coded as a 'yes' and a 'no' in both variables was coded as a 'no'. We analysed the data with logistic regression analysis and report crude frequencies as well as unadjusted and adjusted ORs with 95\% CIs. Family ID was used as a repeated subject because the exposure variables were identical for children from the same family. In another analyses, categorical variables for ETS ('yes'/'no'), water pipe use ('yes'/'no'), incense ('yes'/ 'no'), maternal and paternal participation in labour market (working full time or not) and continuous variables for the number of persons per room in the apartment, child's age, exclusive breast feeding, mother's age at birth, and number of older siblings and were included as independent variables into the model to account for any potential bias from confounding variables. Pets with fur were present in less than $1 \%$ of the homes so this variable was excluded from the analysis. We did an additional analysis where we adjusted estimates associated with general health and mental well-being for asthma. We performed a sensitivity analysis with different definitions of exposure to mould and dampness. All analyses were run on complete case data, that is, individuals with missing data were excluded. All analyses were performed with SAS v9.4 for Windows 8.1 .

\section{RESULTS}

A total of 359 children were recruited, including 161 children from 53 apartments in Herrgården and 198 children from 77 apartments in Törnrosen. The participation rate was $51 \%$ among children identified from the PHCs (the index children) and 32\% among children identified from school class lists. Only one child was identified as both an index child and as a class-list child, and was denoted a class-list child in the analysis. The participants from the two study neighbourhoods were similar with respect to age, sex and exclusive breast feeding (table 1).

The average number of older siblings ( $\geq 14$ years old) was 1.5 in Herrgården and 1.1 in Törnrosen. A larger proportion of the children in Törnrosen were born in Sweden $(91 \%)$ than the children of Herrgairden $(81 \%)$, whereas all parents were born outside Sweden, mainly in Iraq $(32 \%)$, Lebanon $(22 \%)$, and the former Yugoslavia $(17 \%)$. The proportion of mothers with a university education was low in both neighbourhoods $(7 \%$ in Herrgården and $9 \%$ in Törnrosen), whereas the corresponding numbers for the fathers were $10 \%$ and $22 \%$. In Herrgården, there were almost no mothers working full time (4\%), whereas $27 \%$ of the mothers in Törnrosen worked full time. For the fathers, the corresponding numbers were $18 \%$ and $69 \%$ suggesting substantial differences in labour market participation between the two study neighbourhoods (table 1).

Dampness, mould, and cockroaches were frequent in Herrgården and Törnrosen, but as expected they were more common in Herrgården than in Törnrosen (table 2).

The prevalence of any dampness was more common in Herrgården; the average number of factors, for

Table 1 Descriptive statistics of background variables

\begin{tabular}{|c|c|c|c|c|c|}
\hline & \multicolumn{2}{|l|}{ Herrgården } & \multicolumn{2}{|l|}{ Törnrosen } & \multirow[b]{2}{*}{ p Value } \\
\hline & Mean (SD) & Missing (N) & Mean (SD) & Missing (N) & \\
\hline Age (years) & $7.4(3.8)$ & 0 & $6.8(3.8)$ & 0 & 0.14 \\
\hline Exclusive breast feeding (months) & $4.1(2.5)$ & 8 & $3.8(2.6)$ & 6 & 0.28 \\
\hline Mother's age at birth (years) & $29(5)$ & 0 & $27(6)$ & 0 & 0.017 \\
\hline \multirow[t]{2}{*}{ Number of older siblings } & $1.8(1.5)$ & 0 & $1.3(1.1)$ & 0 & 0.0018 \\
\hline & $\mathbf{N}(\%)$ & Missing (N) & $\mathbf{N}(\%)$ & Missing (N) & \\
\hline Girls & $77(48)$ & 0 & $92(46)$ & 0 & 0.92 \\
\hline Born in Sweden & $130(81)$ & 0 & $188(94)$ & 0 & $<0.0001$ \\
\hline Fathers with university education & $16(10)$ & 37 & $44(22)$ & 23 & 0.012 \\
\hline Mothers with university education & $11(7)$ & 22 & $18(9)$ & 0 & 0.84 \\
\hline Fathers working full time & $29(18)$ & 20 & $137(69)$ & 13 & $<0.0001$ \\
\hline Mothers working full time & $6(4)$ & 5 & $53(27)$ & 0 & $<0.0001$ \\
\hline
\end{tabular}


Table 2 Descriptive statistics of housing variables

\begin{tabular}{|c|c|c|c|c|c|}
\hline & \multicolumn{2}{|c|}{ Herrgården } & \multicolumn{2}{|c|}{ Törnrosen } & \multirow[b]{2}{*}{ p Value } \\
\hline & $\mathbf{N}(\%)$ & Missing (N) & $\mathbf{N}(\%)$ & Missing (N) & \\
\hline \multicolumn{6}{|l|}{ Objective exposure assessment } \\
\hline Dampness in kitchen, bath or toilet & $42(79)$ & 1 & $35(45)$ & 0 & $<0.0001$ \\
\hline Dampness in bedrooms or living room & $19(36)$ & 1 & $15(19)$ & 0 & 0.0415 \\
\hline Mould smell or visible mould in bedrooms or living room & $8(15)$ & 1 & $8(10)$ & 0 & 0.42 \\
\hline Visible mould anywhere in the apartment & $21(40)$ & 1 & $10(13)$ & 0 & 0.0006 \\
\hline Mould smell anywhere in the apartment & $20(38)$ & 1 & $17(22)$ & 0 & 0.0495 \\
\hline \multicolumn{6}{|l|}{ Self-reported exposure assessment } \\
\hline Vermin (other than cockroaches) at present & $31(58)$ & 2 & $50(65)$ & 0 & 0.0020 \\
\hline Cockroaches at present & $14(26)$ & 2 & $5(6)$ & 3 & 0.0021 \\
\hline Cockroaches sanitised & $35(66)$ & 3 & $5(6)$ & 10 & $<0.0001$ \\
\hline Father smoking at home & $7(13)$ & 22 & $9(12)$ & 37 & 1 \\
\hline Mother smoking at home & $2(4)$ & 25 & $8(10)$ & 34 & 0.30 \\
\hline Anyone smoking at home & $8(15)$ & 1 & $15(19)$ & 0 & 0.64 \\
\hline Water pipe & $4(8)$ & 1 & $7(9)$ & 1 & 1 \\
\hline \multirow[t]{2}{*}{ Incense } & $29(55)$ & 1 & $14(18)$ & 2 & $<0.0001$ \\
\hline & Mean (SD & & Mean (S & & \\
\hline Persons per room & $1.8(0.6)$ & & $1.7(0.5)$ & & 0.21 \\
\hline $\begin{array}{l}\text { Number of factors indicating dampness in the } \\
\text { kitchen, bathroom and toilet }\end{array}$ & $3.4(2.3)$ & & $1.7(1.7)$ & & $<0.0001$ \\
\hline $\begin{array}{l}\text { Number of factors indicating mould smell or } \\
\text { visible mould in bedrooms or the living room }\end{array}$ & $0.2(0.6)$ & & $0.3(0.7)$ & & 0.43 \\
\hline
\end{tabular}

example, those indicating dampness in the kitchen, bathroom, or toilet was 3.4 in Herrgården and 1.7 in Törnrosen (table 2). Among the self-reported exposure variables, water pipe smoking at home was reported in $9 \%$ of the households of Herrgården and in $8 \%$ of the households of Törnrosen, whereas incense was more common in Herrgården (54\%) than in Törnrosen $(21 \%)$. Exposure to ETS was similar between the two neighbourhoods, and someone smoked indoors in $14 \%$ of the households in Herrgården and in $16 \%$ of the households in Törnrosen (table 2). Crowdedness was similar between the two areas (table 2).

Children with respiratory health problems were oversampled in index children because the original study was designed as a longitudinal intervention study on associations between poor housing conditions and respiratory health. Therefore, we report the frequencies for health outcomes separately for index children, siblings of index children, and class-list children together with their siblings (table 3 ).

The subjective health variables were reported by the mothers of the children. The general health in the classlist children seemed better in Törnrosen where $88 \%$ had good or very good health according to their mothers. The corresponding number in Herrgården was $70 \%$ (table 3). The proportion of class-list children with a positive SPT, which was the only objective (not selfreported) health measure in this study, was similar between the two neighbourhoods at $13 \%$ in Herrgården and $12 \%$ in Törnrosen. Among class-list children in
Herrgården $11 \%$ had been seeking emergency care two times or more the previous 3 months compared with $9 \%$ in Törnrosen. The proportion of class-list children in Herrgården who had two or more reported colds the previous 3 months was $31 \%$, and in Törnrosen this was 24\%. In Herrgården, $16 \%$ of the class-list children's mothers reported their child to have had otitis media at least once during the previous 3 months compared with $17 \%$ in Törnrosen. Stomach ache and fatigue were more common in Herrgården than in Törnrosen whereas concentration difficulties and stress were more often reported in Törnrosen than in Herrgården (table 3).

When investigating associations between health and housing conditions using logistic regression analysis, the results were generally inconclusive (the CIs of the estimated ORs often included $\mathrm{OR}=1$; table 4). However, current asthma was associated with dampness $(\mathrm{OR}=4.06$, $95 \%$ CI 1.23 to 6.39 ) when adjusted for other risk factors, as was asthma medication $(\mathrm{OR}=2.81,95 \%$ CI 1.23 to 6.39 ). Moreover, there was a negative association between mould and good general health $(\mathrm{OR}=0.32$, 95\% CI 0.11 to 0.96 ) and between mould and headache $(\mathrm{OR}=4.20,95 \%$ CI: 1.19 to 14.8$)$ when adjusted for other risk factors. The ORs for concentration difficulties, difficulty falling asleep and fatigue in association with mould were high but not statistically significant. Presence of cockroaches was negatively associated with a good general health ( $\mathrm{OR}=0.36,95 \%$ CI 0.14 to 0.93$)$, and with seeking emergency care the previous months with an OR of 4.88 (95\% CI 1.63 to 14.6), and with the 
Table 3 Descriptive statistics of outcome variables in Herrgården and Törnrosen for children by category

\begin{tabular}{|c|c|c|c|c|c|c|c|}
\hline & \multicolumn{3}{|c|}{ Herrgården N (\%) } & \multicolumn{3}{|c|}{ Törnrosen N (\%) } & \multirow[b]{2}{*}{$\begin{array}{l}\text { Total N } \\
(\%) / m i s s i n g\end{array}$} \\
\hline & $\begin{array}{l}\text { Index } \\
\text { child }\end{array}$ & $\begin{array}{l}\text { Sibling of } \\
\text { index child }\end{array}$ & Schoolchild & $\begin{array}{l}\text { Index } \\
\text { child }\end{array}$ & $\begin{array}{l}\text { Sibling of } \\
\text { index child }\end{array}$ & Schoolchild & \\
\hline Good general health & $23(61)$ & $46(87)$ & $49(70)$ & $30(64)$ & $50(76)$ & $75(88)$ & $273(76) / 2$ \\
\hline Positive skin prick test & $4(11)$ & $5(9)$ & $9(13)$ & $4(9)$ & $6(9)$ & $10(12)$ & $38(11) / 0$ \\
\hline Current asthma & $15(63)$ & $3(13)$ & $6(25)$ & $22(47)$ & $4(6)$ & $6(7)$ & $56(16) / 21$ \\
\hline Asthma medication & $18(47)$ & $1(2)$ & $2(3)$ & $29(62)$ & $3(5)$ & $1(1)$ & $54(15) / 14$ \\
\hline $\begin{array}{l}\geq 2 \text { instances of emergency } \\
\text { care in the previous } \\
3 \text { months }\end{array}$ & $9(24)$ & $6(11)$ & $8(11)$ & $6(13)$ & $6(9)$ & $6(9)$ & $41(11) / 2$ \\
\hline $\begin{array}{l}\geq 2 \text { colds in the previous } \\
3 \text { months }\end{array}$ & $17(45)$ & $20(38)$ & $22(31)$ & $22(47)$ & $20(30)$ & $20(24)$ & $121(34) / 2$ \\
\hline $\begin{array}{l}\text { Otitis media in the previous } \\
3 \text { months }\end{array}$ & $14(37)$ & $5(9)$ & $11(16)$ & $7(15)$ & $9(14)$ & $14(17)$ & $60(17) / 2$ \\
\hline Headache & $2(5)$ & $13(25)$ & $19(27)$ & $6(13)$ & $14(21)$ & $22(26)$ & $76(21) / 14$ \\
\hline Stomach ache & $6(16)$ & $12(23)$ & $24(34)$ & $17(36)$ & 19 (29) & $25(29)$ & $103(29) / 13$ \\
\hline Stress & $0(0)$ & $5(9)$ & $1(1)$ & $4(9)$ & 8 (12) & $6(7)$ & $24(7) / 15$ \\
\hline Concentration difficulties & $1(3)$ & $6(11)$ & $2(3)$ & $4(9)$ & $3(5)$ & $7(8)$ & $23(6) / 14$ \\
\hline Difficulty falling asleep & $0(0)$ & 7 (13) & $6(9)$ & $5(11)$ & $7(11)$ & $9(11)$ & $34(9) / 13$ \\
\hline Fatigue & $2(5)$ & $11(21)$ & $9(13)$ & $10(21)$ & $13(20)$ & $12(14)$ & $57(16) / 13$ \\
\hline
\end{tabular}

number of colds the previous 3 months $(\mathrm{OR}=2.87,95 \%$ CI 1.01 to 8.2$)$, and with headaches ( $\mathrm{OR}=5.2,95 \%$ CI 1.93 to 13.9 ), as well as with difficulty falling asleep $(\mathrm{OR}=8.61,95 \%$ CI 2.52 to 29.4 ; table 4$)$. The ORs of stomach ache, concentration difficulties and fatigue in association with presence of cockroaches were elevated, but not statistically significant. In the additional analysis when current asthma and SPT were included as dependent variables, the ORs were often somewhat attenuated, but the conclusions were similar (data not shown).

Crowdedness did not seem to be associated with any of the outcomes investigated here.

The results of the sensitivity analysis with different definitions of exposure to mould and dampness did not change the estimates substantially (data not shown). Crude ORs stratified by study neighbourhood are presented in online supplementary files 1A-C.

\section{DISCUSSION}

In this cross-sectional study on poor housing conditions in association with child health in a disadvantaged immigrant population in Rosengård, Malmö, Sweden, housing conditions seemed to be associated with general health and asthma as observed by other, as well as with indicators for mental well-being, which is less evident from existing literature.

The housing conditions of the children were very poor with a high prevalence of cockroaches, especially in the study neighbourhood Herrgården, where $67 \%$ of the apartments had been sanitised from cockroaches and $27 \%$ of the apartments were infested with cockroaches at the time of the study. In the second study area, Törnrosen, cockroaches were present in only $6 \%$ of the households. Mould and dampness were also more common in Herrgården where mould was visible in $40 \%$ of the apartments compared with $13 \%$ in Törnrosen. Moreover, the general health of the children in Herrgården seemed poorer than in Törnrosen and in the general population of the county with only $70 \%$ of the schoolchildren in Herrgården but $88 \%$ in Törnrosen reported to have 'Good' or 'Very Good' health. The corresponding numbers for the county of Scania were $95 \%$ for 12-year-olds, $89 \%$ for 4-year-olds, and $91 \%$ for 8 month-old babies according to a national child survey from 2011. ${ }^{18}$ The health of first-generation adult immigrants has been reported to be better than that of a comparable population in the country of arrival, and this is referred to as the 'immigrant paradox'. ${ }^{19}{ }^{20}$ However, it is uncertain whether this is true for children, and poverty and economic disadvantages are more common in immigrant populations, and subsequent generations in general do not have better health than the average population of the country of arrival. In fact, according to a local report in Malmö, immigrants are clearly underrepresented in terms of healthcare utilisation despite the fact that numerous risk factors are over-represented. ${ }^{21}$ In this study, where the children mostly were born in Sweden with parents who immigrated to Sweden, the self-reported health in general was worse than that of a comparable population. ${ }^{18}$

The focus of this study was to describe the home environment of the study population and to describe associations between various health outcomes and different aspects of the home environment. When adjusted for other factors, current asthma and asthma medication seemed to be associated with dampness, and mould was associated with worse general health and with headache, results that are in line with existing literature. ${ }^{5} 689$ 22-25 The association between the presence of cockroaches 


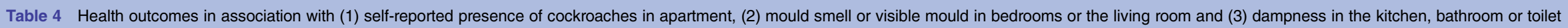

\begin{tabular}{|c|c|c|c|c|c|c|c|c|c|c|c|c|c|c|c|c|c|c|}
\hline \multirow{4}{*}{ Good general health } & \multicolumn{6}{|c|}{ Cockroaches } & \multicolumn{6}{|l|}{ Mould } & \multicolumn{6}{|c|}{ Dampness } \\
\hline & \multirow{2}{*}{\multicolumn{2}{|c|}{$\begin{array}{l}\text { Yes No } \\
\text { Case/ } \\
\text { non-case* }\end{array}$}} & \multirow{3}{*}{$\begin{array}{l}\text { ORt } \\
0.77\end{array}$} & \multirow{3}{*}{$\begin{array}{l}95 \% \text { Cl } \\
0.34 \text { to } 1.74\end{array}$} & \multirow{3}{*}{$\begin{array}{l}\text { OR } \\
0.36\end{array}$} & \multirow{3}{*}{$\begin{array}{l}95 \% \mathrm{Cl} \\
0.14 \text { to } 0.93\end{array}$} & \multirow{2}{*}{\multicolumn{2}{|c|}{$\begin{array}{l}\text { Yes No } \\
\text { Case/ } \\
\text { non-case* }\end{array}$}} & \multirow{3}{*}{$\begin{array}{l}\text { OR† } \\
0.61\end{array}$} & \multirow{3}{*}{$\begin{array}{l}95 \% \mathrm{Cl} \\
0.25 \text { to } 1.50\end{array}$} & \multirow{3}{*}{$\begin{array}{l}\text { OR } \\
0.32\end{array}$} & \multirow{3}{*}{$\begin{array}{l}95 \% \mathrm{Cl} \\
0.11 \text { to } 0.96\end{array}$} & \multirow{2}{*}{\multicolumn{2}{|c|}{$\begin{array}{l}\text { Yes No } \\
\text { Casel } \\
\text { non-case* }\end{array}$}} & \multirow{3}{*}{$\begin{array}{l}\text { ORt } \\
0.59\end{array}$} & \multirow{3}{*}{$\begin{array}{l}95 \% \mathrm{Cl} \\
0.21 \text { to } 1.12\end{array}$} & \multirow{3}{*}{$\begin{array}{l}\text { OR‡ } \\
0.60\end{array}$} & \multirow{3}{*}{$\begin{array}{l}95 \% \mathrm{Cl} \\
0.29 \text { to } 1.22\end{array}$} \\
\hline & & & & & & & & & & & & & & & & & & \\
\hline & $40 / 14$ & $233 / 64$ & & & & & $25 / 11$ & $248 / 67$ & & & & & $161 / 55$ & $112 / 23$ & & & & \\
\hline Positive skin prick test & $7 / 49$ & $31 / 271$ & 1.16 & 0.45 to 3.03 & 0.87 & 0.19 to 3.93 & $3 / 33$ & $35 / 287$ & 0.66 & 0.16 to 2.79 & 0.57 & 0.21 to 4.26 & $24 / 188$ & $14 / 122$ & 1.01 & 0.47 to 2.19 & 0.71 & 0.32 to 1.58 \\
\hline Current asthma & $8 / 39$ & $48 / 188$ & 0.81 & 0.31 to 2.07 & 1.96 & 0.66 to 5.83 & $6 / 24$ & $50 / 202$ & 1.03 & 0.40 to 2.67 & 1.37 & 0.40 to 4.66 & $44 / 136$ & $12 / 90$ & 2.41 & 1.18 to 4.95 & 4.06 & 1.67 to 9.87 \\
\hline Asthma medication & $6 / 43$ & $48 / 212$ & 0.61 & 0.24 to 1.52 & 0.82 & 0.21 to 1.93 & $5 / 26$ & $49 / 229$ & 0.91 & 0.34 to 2.41 & 0.79 & 0.27 to 2.34 & $42 / 150$ & $12 / 105$ & 2.44 & 1.28 to 4.64 & 2.81 & 1.23 to 6.39 \\
\hline $\begin{array}{l}\geq 2 \text { instances of } \\
\text { emergency care in the } \\
\text { previous } 3 \text { months }\end{array}$ & $10 / 45$ & $31 / 266$ & 1.93 & 0.78 to 4.78 & 4.88 & 1.63 to 14.63 & $6 / 30$ & $35 / 281$ & 1.51 & 0.47 to 4.90 & 1.32 & 0.38 to 4.58 & $27 / 191$ & $14 / 120$ & 1.19 & 0.55 to 2.57 & 1.47 & 0.51 to 4.24 \\
\hline $\begin{array}{l}\geq 2 \text { colds in the } \\
\text { previous } 3 \text { months }\end{array}$ & $22 / 33$ & 109/199 & 1.41 & 0.63 to 3.16 & 2.87 & 1.01 to 8.18 & $17 / 19$ & $104 / 213$ & 1.76 & 0.64 to 4.84 & 2.14 & 0.67 to 6.86 & $78 / 140$ & $43 / 92$ & 1.15 & 0.65 to 2.04 & 0.99 & 0.50 to 1.56 \\
\hline $\begin{array}{l}\text { Otitis media in the } \\
\text { previous } 3 \text { months }\end{array}$ & $14 / 41$ & $46 / 252$ & 2.02 & 0.90 to 4.54 & 2.18 & 0.82 to 5.80 & $7 / 29$ & $53 / 264$ & 1.21 & 0.44 to 3.33 & 0.98 & 0.26 to 3.63 & $41 / 177$ & $19 / 126$ & 1.43 & 0.78 to 2.64 & 1.12 & 0.54 to 2.34 \\
\hline Headache & $21 / 28$ & $55 / 206$ & 2.77 & 1.14 to 6.71 & 5.16 & 1.93 to 13.92 & $11 / 20$ & $137 / 129$ & 1.91 & 0.69 to 5.31 & 4.20 & 1.19 to 14.81 & $46 / 148$ & $30 / 86$ & 0.94 & 0.51 to 1.75 & 0.82 & 0.39 to 1.74 \\
\hline Stomach ache & $19 / 30$ & $74 / 179$ & 1.30 & 0.59 to 2.90 & 2.44 & 0.90 to 6.59 & $10 / 21$ & $93 / 188$ & 0.98 & 0.38 to 2.54 & 1.61 & 0.51 to 5.03 & $65 / 130$ & $38 / 89$ & 1.02 & 0.56 to 1.84 & 1.25 & 0.62 to 2.52 \\
\hline Stress & $8 / 41$ & $16 / 242$ & 2.19 & 0.58 to 8.64 & - & & $3 / 27$ & $39 / 227$ & 1.05 & 0.22 to 5.07 & - & & $11 / 182$ & $13 / 101$ & 0.53 & 0.19 to 1.50 & - & \\
\hline $\begin{array}{l}\text { Concentration } \\
\text { difficulties }\end{array}$ & $4 / 44$ & $19 / 241$ & 1.15 & 0.40 to 3.34 & 1.76 & 0.52 to 5.96 & $3 / 28$ & $20 / 258$ & 1.38 & 0.40 to 4.73 & 3.91 & 0.91 to 16.71 & $15 / 177$ & $8 / 108$ & 1.14 & 0.47 to 2.76 & 1.62 & 0.55 to 4.80 \\
\hline Difficulty falling asleep & $11 / 38$ & $23 / 240$ & 2.90 & 1.23 to 6.81 & 8.61 & 2.52 to 29.43 & $4 / 27$ & $30 / 251$ & 1.28 & 0.43 to 3.80 & 2.40 & 0.66 to 8.76 & 19/176 & 15/102 & 0.74 & 0.33 to 1.64 & 0.92 & 0.36 to 2.34 \\
\hline Fatigue & $14 / 35$ & $43 / 220$ & 1.68 & 0.64 to 4.38 & 2.85 & 0.89 to 9.17 & 9/22 & $48 / 233$ & 1.91 & 0.66 to 5.50 & 2.30 & 0.60 to 8.87 & $36 / 159$ & $21 / 86$ & 1.10 & 0.53 to 2.30 & 1.35 & \\
\hline
\end{tabular}


and various health outcomes (including worse general health, emergency care visits, headache, and difficulty falling asleep) and tendencies of associations with stomach ache, concentration difficulties and fatigue are interesting and have not been reported previously to our knowledge. The presence of cockroaches could be an indicator of factors in the environment that are related to mental well-being. Crowdedness is a tentative factor, but the estimates were adjusted for the number of persons per room in the apartment, and crowdedness in itself was not associated with any of the outcomes investigated here. Ventilation has been observed in previous studies to reduce symptoms of headaches and fatigues in adults, ${ }^{26}$ and cockroaches have previously been observed to be associated with wheeze. ${ }^{27}$ There is previous scientific evidence for housing to affect mental health as described in a review from $2003,{ }^{28}$ but many studies have weaknesses when it comes to assessing causality. ${ }^{29}$ Large prospective longitudinal studies with random effects for different types of neighbourhoods are still lacking.

Multiple comparisons have to be considered in this study, and the results should be interpreted with caution, and as hypothesis generating. The study population is disadvantaged compared with the average Swedish population and the generalisability of the results to other populations is thus uncertain. Subjective health symptoms in Sweden have previously been observed to be more frequent in children with a foreign parental background, ${ }^{30}$ which could either be explained by differences in inclination to report health symptoms or in differences in morbidity between children with and without an immigrant background. Representativity of the study population is uncertain because the participation rates were rather low at $51 \%$ among children identified at the PHCs (index children) and only 32\% among children identified through the local schools. Subjective health symptoms were assessed though parental reporting, as were diagnoses. Interestingly, we observed no association between any of the exposures and the only nonsubjective health outcome in the study, a positive SPT. Furthermore, the outcomes are not independent of each other. For example, asthma and allergy are associated with general health, sleeping problems, otitis media, fatigue and headaches. A possibility would have been to adjust the estimates for other outcomes, but we chose not to do that, mainly because causal directions between the different outcomes are ambiguous. Therefore, when interpreting the results of this study it is important to have in mind that the ORs were not adjusted for other outcomes and that this may cause residual confounding. In an additional analysis we adjusted for general health, otitis media, stomach ache, fatigue, difficulties falling asleep, concentration difficulties and stress for current asthma, which mostly resulted in somewhat attenuated ORs, but the conclusions were not altered.

Accuracy of questionnaire reports when assessing home environment exposures has been challenged. ${ }^{31}$
Therefore, a major strength of the study is that the exposure assessment for mould and dampness was objectively assessed by health communicators. In fact, the agreement between self-reported variables and objectively assessed variables were only fair-to-moderate in this study. ${ }^{32}$ Regarding cockroaches, there was no objectively assessed information. This variable might therefore be prone to bias due to selective reporting. Given that the health variables are also self-reported the results of health in association with cockroach exposure could be especially sensitive to selective reporting bias and should be interpreted with care.

The quality of exposure would benefit from measurements, ${ }^{31}$ and there were many factors lacking that could have been taken into account. For example, we did not have sufficient information on the type of carpets in the household, which has been observed to be an important factor to consider when investigating associations between asthma symptoms and dampness. ${ }^{10}$ Furthermore, the amount of data regarding exposure was large, and exposure to mould and dampness could have been defined in many different ways. The sensitivity analysis we performed revealed no substantial differences in our conclusions, but the estimates were not easily comparable given the low inherent statistical power in this study.

In conclusion, we have described the home environment for a study population on the margin of Swedish society, and we have observed interesting tendencies for associations between the presence of cockroaches and outcomes related to general health and mental wellbeing. Furthermore, we observed associations between dampness and asthma, and associations between mould and general health and headaches, which are in line with current knowledge. Despite the weaknesses of the study, the results provide a strong indication for the direction of future research in this study population. Poor housing conditions are a strategic opportunity for intervention, ${ }^{2}$ and housing conditions were poor in the both study neighbourhoods. Children's health will, therefore, be studied in both study neighbourhoods in prospective longitudinal studies with data from national and local registers, and this will decrease the limitations of selfreported data in this study.

Acknowledgements The authors wish to thank the study participants, and personnel from the PHCs in Rosengård and Törnrosen. The field work could not have been carried out without the excellent help from Harriet Persson, Sabile Zenulahu, Naima Muhamud and Sara Grané. Registered nurses from the Department of Occupational and Environmental Medicine, Lund performed the skin prick tests.

Contributors KJ conceived and designed the study. LA-n was responsible for recruitment of study participants, and one of the field investigators. JCR and TT participated in data collection. AO did the statistical analysis. AO and JCR drafted the manuscript. All the authors participated in writing of the final version of the manuscript.

Funding The research was funded from Region Skåne, and from Formas, grant nr 219-2010-1207. 
Competing interests None declared.

Ethics approval Ethical approval for the study was granted by the Regional Ethical Review Board through Lund University (Registration number 2010/212).

Provenance and peer review Not commissioned; externally peer reviewed.

Data sharing statement Additional data can be accessed via the Dryad data repository at http://datadryad.org/ with the doi:10.5061/dryad.802hc

Open Access This is an Open Access article distributed in accordance with the Creative Commons Attribution Non Commercial (CC BY-NC 4.0) license, which permits others to distribute, remix, adapt, build upon this work noncommercially, and license their derivative works on different terms, provided the original work is properly cited and the use is non-commercial. See: http:// creativecommons.org/licenses/by-nc/4.0/

\section{REFERENCES}

1. Perera F, Viswanathan S, Whyatt R, et al. Children's environmental health research-highlights from the Columbia Center for Children's Environmental Health. Ann N Y Acad Sci 2006;1076:15-28.

2. Krieger J, Higgins DL. Housing and health: time again for public health action. Am J Public Health 2002;92:758-68.

3. Sengoelge M, Hasselberg M, Ormandy D, et al. Housing, income inequality and child injury mortality in Europe: a cross-sectional study. Child Care Health Dev 2014;40:283-91.

4. Marmot M. Social determinants of health inequalities. Lancet 2005;365:1099-104.

5. Bornehag CG, Sundell J Bonini S, et al. Dampness in buildings as a risk factor for health effects, EUROEXPO: a multidisciplinary review of the literature (1998-2000) on dampness and mite exposure in buildings and health effects. Indoor Air 2004;14:243-57.

6. Braubach M, Jacobs DE, Ormandy D. Environmental burden of disease associated with inadequate housing. Methods for quantifying health impacts of selected housing risks in the WHO European region. Summary report, WHO, 2011.

7. Choi J, Chun C, Sun Y, et al. Associations between building characteristics and children's allergic symptoms-a cross-sectional study on child's health and home in Seoul, South Korea. Build Environ 2014;75:176-81.

8. Heinrich J. Influence of indoor factors in dwellings on the development of childhood asthma. Int J Hyg Environ Health 2011;214:1-25.

9. Peat JK, Dickerson J, Li J. Effects of damp and mould in the home on respiratory health: a review of the literature. Allergy 1998;53:120-8.

10. Wang TT, Zhao ZH, Yao $\mathrm{H}$, et al. Housing characteristics and indoo environment in relation to children's asthma, allergic diseases and pneumonia in Urumqi, China. Chin Sci Bull 2013;58:4237-44.

11. Rosenstreich DL, Eggleston $\mathrm{P}$, Kattan $\mathrm{M}$, et al. The role of cockroach allergy and exposure to cockroach allergen in causing morbidity among inner-city children with asthma. N Engl J Med 1997;336:1356-63.

12. Salonen T. Barns ekonomiska utsatthet. Stockholm: Save the Children Sweden, 2010.

13. Marcus L. Social housing and segregation in Sweden: from residential segregation to social integration in public space. Prog Plann 2007;67:251-63.
14. Köhler M. Barn i Malmö. Skilda livsvillkor ger ojämlik hälsa. Ett diskussionsunderlag framtaget för Komissionen för ett socialt hållbart Malmö: Kommission för ett socialt hållbart Malmö. Malmö stad, 2012.

15. Barnen R. Barnfattigdom i Sverige. Rädda Barnen, 2014.

16. Albin M, Jakobsson K, Djurfeldt A. Miljöns betydelse för sociala skillnader i hälsa. Malmö: Malmö Stad, 2012.

17. Munir AKM, Björkstén B, Einarsson R, et al. Cat (Fel d I), dog (Can f $\mathrm{I})$, and cockroach allergens in homes of asthmatic children from three climatic zones in Sweden. Allergy 1994;49:508-16.

18. Jakobsson KJ, et al. Barn, Miljö och Hälsa. En rapport från Skåne, Blekinge och Kronobergs län 2013, 2013. http://www.lansstyrelsen. se/blekinge/Sv/publikationer/rapporter/2014/Pages/barn-miljo-halsa. aspx (accessed 1 Dec 2015).

19. Fennelly K. The "healthy migrant" effect. Minn Med 2007; 90:51-3.

20. Mendoza FS. Health disparities and children in immigrant families: a research agenda. Pediatrics 2009;124(Suppl 3):S187-95.

21. Kommission för ett socialt hållbart Malmö. Malmös väg mot en hållbar framtid. http://malmo.se/download/18.3108a6ec1445513e 589b90/1393252127222/malmo\%CC\%88kommissionen_ slutrapport_2014.pdf (accessed 1 Dec 2015).

22. Statistikrapport 2004 - statistisk uppfoljning av Rapport Integration, 2003.

23. Hyndman SJ. Housing dampness and health amongst British Bengalis in East London. Soc Sci Med 1990;30:131-41.

24. Koskinen OM, Husman TM, Meklin TM, et al. The relationship between moisture or mould observations in houses and the state of health of their occupants. Eur Respir J 1999;14:1363-7.

25. Platt SD, Martin CJ, Hunt SM, et al. Damp housing, mould growth, and symptomatic health state. BMJ 1989;298:1673.

26. Norbäck D, Nordström K, Zhao Z. Carbon dioxide $\left(\mathrm{CO}_{2}\right)$ demand-controlled ventilation in university computer classrooms and possible effects on headache, fatigue and perceived indoor environment: an intervention study. Int Arch Occup Environ Health 2013;86:199-209.

27. Gold DR, Burge HA, Carey V, et al. Predictors of repeated wheeze in the first year of life: the relative roles of cockroach, birth weight, acute lower respiratory illness, and maternal smoking. Am J Respir Crit Care Med 1999;160:227-36.

28. Evans GW, Wells NM, Moch A. Housing and mental health: a review of the evidence and a methodological and conceptual critique. $J$ Soc Issues 2003;59:475-500.

29. Evans GW, Kantrowitz E. Socioeconomic status and health: the potential role of environmental risk exposure. Annu Rev Public Health 2002;23:303-31.

30. Carlerby H, Viitasara E, Knutsson A, et al. Subjective health complaints among boys and girls in the Swedish HBSC study: focussing on parental foreign background. Int $J$ Public Health 2011;56:457-64.

31. Dales RE, Miller D, McMullen E. Indoor air quality and health: validity and determinants of reported home dampness and moulds. Int J Epidemiol 1997;26:120-5.

32. Richter JC, Jakobsson K. Identifying potentially unhealthy housing conditions in Rosengård-a cross-sectional study in immigrant households with small children in Sweden, 2013. http://lup.lub.lu.se/ luur/download?func=downloadFile\&recordOld=4191766\&fileOld= 4191768 (accessed 1 Dec 2015). 